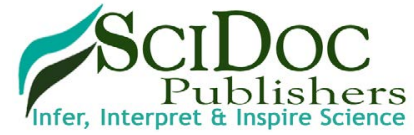

International Journal of Behavioral Research \& Psychology
ISSN 2332-3000

(IJBRP)

\title{
Rehabilitative Solutions for Promoting Independence and Self-Determination of Children with Cornelia de Lange Syndrome
}

Editorial

\author{
Stasolla $\mathrm{F}^{1^{*}}$, Perilli $\mathrm{V}^{2}$ \\ ${ }^{1}$ Department of Neurosciences, University of Bari, Italy. \\ ${ }^{2}$ Lega del Filo d'Oro Research Center, Molfetta, Italy.
}

Cornelia de Lange syndrome $(\mathrm{CdL})$ is a congenital disorder characterized by multiple disabilities. It includes growth delays, behavioral abnormalities, both hands and feet problems, intellectual difficulties, autistic features, stereotypic movements, language deficits, self-injuries [1,2]. Although there is a substantial variance in its phenotype, the majority of $\mathrm{CdL}$ individuals are socially, communicatively and cognitively impaired, ranging between the moderate and the profound level of developmental disabilities [3]. Microcephaly, highly arched eyebrows, long and thick eyelashes, short neck, hirsute ears with thickened helices, small widely-spaced teeth, arched palate with clefts, downturned mouth corners are physical traits commonly described [4]. The diagnosis is usually based upon clinical grounds. Specifically, positive mutation on $\mathrm{CdL}$ gene testing or facial findings and meet-criteria such as development and behavior basic points (e.g., learning difficulties, attention deficits hyperactivity disorders, anxiety, withdrawal, impulsive behavior, roaming, obsessivecompulsive features) should be considered $[5,7]$. Accordingly, a primary rehabilitative goal of $\mathrm{CdL}$ children is the independence and self-determination towards their environment because they constantly rely on parents and/or caregivers' assistance due to their pathology [8-10]. One way to pursue the latter objective, is the use of cognitive-behavioral interventions [11, 12]. Eventually, assistive technology-based program should be implemented [13, 14].

Cognitive-behavioral rehabilitative strategies are frequently based upon learning principles (i.e., causal association between behavioral responding and environmental consequences), for enabling children with multiple and/or severe to profound developmental disabilities with the awareness of their own behavior and enhancing it to be functional for getting independent access to positive stimulation $[15,16]$. Within this framework, AT refers to any piece, device, equipment or tool fostering the autonomy of participants involved in the rehabilitative packages. Furthermore, augmentative alternative communication (AAC) aided-options may be useful and helpful for improving communication skills
[17]. Positive outcomes may have beneficial effects on children's quality of life [18]. Moreover, both parents and caregivers' burden might be significantly reduced [20].

Depending upon participants' levels of functioning and their general and/or clinical conditions, both economical and human resources, and the rehabilitative aims, one may envisage different typologies of solutions. For instance, early intensive behavioral interventions may be successful for both reducing aggression, and self-injuries, and re-direct participants' behavior profitably for the acquisition of new adaptive skills [19]. Eventually, a functional assessment of the challenging behavior may be meaningful [20]. Else, one may implement a cluster technology for reaching the dual goal of increasing an adaptive responding and decreasing a challenging behavior [21]. Otherwise, a microswitch-based program with contingent stimulation may be implemented for facilitating locomotion and/or its fluency [22]. AAC-based programs such as PECS and VOCA or computer-assisted options may be adopted for promoting the independent communication of both personal needs and academic performances [23-25]. Additionally, occupation purposes through AT may be achieved $[26,27]$. Finally, social validation assessments by external sensitive raters and indices of happiness and/or positive participation as outcome measures of the quality of life may be carried out [2830].

In light of the above, new research perspectives within this area should deal with the following topics: (a) extend the use of both cognitive-behavioral interventions and AT-based programs to new individuals with $\mathrm{CdL}$ syndrome, because the current literature on this specific framework is lacking, (b) find out new updated and individualized technological solutions for each CdL participant, (c) conduct new social validation assessments involving parents, students, physicians, teachers and caregivers as expert external raters, and (d) consider indices of happiness and/or positive participation as outcome measures of participants' quality of life as to corroborate the intervention's clinical and practical validity.

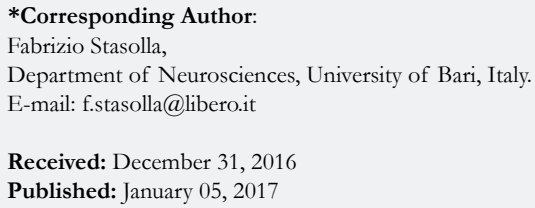

Copyright: Stasolla $\mathbf{F}^{\circ}$ 2017. This is an open-access article distributed under the terms of the Creative Commons Attribution License, which permits unrestricted use, distribution and reproduction in any medium, provided the original author and source are credited. 


\section{References}

[1]. Parisi L, Di Filippo T, Roccella M (2015) Behavioral phenotype and autism spectrum disorders in Cornelia de Lange syndrome. Ment Illn. 7(2): 5988.

[2]. Lanovaz MJ, Rapp JT, Maciw I (2014) Assessment and treatment of stereotypy in an individual with Cornelia de Lange syndrome and deaf blindness. J Intellect Dev Disabil. 3(4): 375-80.

[3]. Powis L, Oliver C (2014) The prevalence of aggression in genetic syndromes: A review. Res Dev Disabil. 35(5): 1051-71.

[4]. Oliver C, Adams D, Allen D, Bull L, Heald M, et al., (2013) Causal Models of Clinically Significant Behaviors in Angelman, Cornelia de Lange, PraderWilli and Smith-Magenis Syndromes. Int Rew Res Dev Disabil. 44: 169211.

[5]. Moss J, Oliver C, Nelson L, Richards C, Hall S (2013) Delineating the profile of autism spectrum disorder characteristics in Cornelia de Lange and fragile x syndromes. Am J Intellect Dev Disabil. 118(1): 55-73.

[6]. Nakanishi M, Deardorff MA, Clark D, Levy SE, Krantz I, et al., (2012) Investigation of autistic features among individuals with mild to moderate Cornelia de Lange syndrome. Am J Med Genet Part A. 158(8): 1841-7.

[7]. Richman DM, Belmont JM, Kim M, Slavin CB, Hayner AK (2009) Parenting stress in families of children with Cornelia de Lange syndrome and down syndrome. J Dev Phys Disabil. 21: 537-53.

[8]. Hall SS, Arron K, Sloneem J, Oliver C (2008) Health and sleep problems in Cornelia de Lange syndrome: A case control study. J Intellect Disabil Res. 52(5): 458-68.

[9]. Cossu MC, Nava I, Leoni S, Piccardi L (2005) Neuropsychological rehabilitation in a case of Cornelia de Lange syndrome. Neuropsychol Rehabil. 15(2): $147-60$

[10]. Sarimski K (2002) Analysis of intentional communication in severely handicapped children with Cornelia-de-Lange syndrome. J Commun Disord. 35(6): 483-500.

[11]. Stasolla F, Perilli V, Damiani R, Albano V (2016) Assistive technology to promote occupation and reduce mouthing by three boys with fragile X syndrome. Dev Neurorehabil. 1-9.

[12]. Stasolla F, Perilli V (2015) Assistive technology to promote communication, leisure and occupation skills for children with Rett syndrome and severe to profound developmental disabilities: A literature overview. Rett Syndrome and Other Communication Disorders: Symptoms, Treatment and Prognosis. $159-80$

[13]. Stasolla F, Perilli V, Boccasini A (2016) Assistive Technologies for Persons with Severe-Profound Intellectual and Developmental Disabilities. Computer-Assisted and Web-Based Innovations in Psychology, Special Education, and Health. 287-310.

[14]. Stasolla F, Perilli V (2015) Microswitch-based programs (MBP) to promote communication, occupation, and leisure skills for children with multiple disabilities: A literature overview. Recent Advances in Assistive Technologies to Support Children with Developmental Disorders. 195-216.

[15]. Lancioni GE, O'Reilly MF, Singh NN, Stasolla F, Manfredi F, et al., (2004) Adapting a grid into a microswitch to suit simple hand movements of a child with profound multiple disabilities. Percept Mot Skills. 99(2): 724-8.

[16]. Stasolla F, Boccasini A, Perilli V, Caffò AO, Damiani R, et al., (2014) A selective overview of microswitch-based programs for promoting adaptive behaviors of children with developmental disabilities. Int J Ambient Comput Intell. 6(2): 56-74.

[17]. Lorah ER (2016) Comparing teacher and student use and preference of two methods of augmentative and alternative communication: Picture exchange and a speech-generating device. J Dev Phys Disabil. 28(5): 751-67.

[18]. Midtlin HS, Næss K-B, Taxt T, Karlsen AV (2015) What communication strategies do AAC users want their communication partners to use? A preliminary study. Disabil Rehabil. 37(14): 1260-7.

[19]. Matson JL, Tureck K, Turygin N, Beighley J, Rieske R (2012) Trends and topics in early intensive behavioral interventions for toddlers with autism. Res Autism Spectr Disord. 6(4): 1412-7.

[20]. Madsen EK, Peck JA, Valdovinos MG (2016) A review of research on directcare staff data collection regarding the severity and function of challenging behavior in individuals with intellectual and developmental disabilities. J Intellect Disabil. 20(3): 296-306.

[21]. Stasolla F, Perilli V, Damiani R, Caffò AO, Di Leone A, et al., (2014) A microswitch-cluster program to enhance object manipulation and to reduce hand mouthing by three boys with autism spectrum disorders and intellectual disabilities. Res Autism Spectr Disord. 8: 1071-8.

[22]. Stasolla F, Caffo AO (2013) Promoting adaptive behaviors by two girls with Rett syndrome through a microswitch-based program. Res Autism Spectr Disord. 7(10): 1265-72.

[23]. Stasolla F, Caffò AO, Picucci L, Bosco A (2013) Assistive technology for promoting choice behaviors in three children with cerebral palsy and severe communication impairments. Res Dev Disabil. 34(9): 2694-700.

[24]. Stasolla F, Damiani R, Perilli V, D'Amico F, Caffo AO, et al., (2015) Computer and microswitch-based programs to improve academic activities by six children with cerebral palsy. Res Dev Disabil. 45-46: 1-13.

[25]. Stasolla F, De Pace C, Damiani R, Di Leone A, Albano V, et al., (2014) Comparing PECS and VOCA to promote communication opportunities and to reduce stereotyped behaviors by three girls with Rett syndrome. Res Autism Spectr Disord. 8(10): 1269-78.

[26]. Lancioni GE, Singh NN, O'Reilly MF, Sigafoos J, Alberti G, et al., (2015) Assistive technology to support occupational engagement and mobility in persons with multiple disabilities. Life Span Disabil. 18(1): 119-39.

[27]. Lancioni GE, Singh NN, O'Reilly MF, Sigafoos J, D'Amico F, et al., (2014) Technology to help persons with extensive neuro-motor impairment and lack of speech with their leisure occupation and communication. Res Dev Disabil. 35(3): 611-8.

[28]. Stasolla F, Perilli V, Caffò AO, Boccasini A, Stella A, et al., (2016) Extending microswitch-cluster programs to promote occupation activities and reduce mouthing by six children with autism spectrum disorders and intellectual disabilities. J Dev Phys Disabil. 1-18.

[29]. Stasolla F, Caffò AO, Damiani R, Perilli V, Di Leone A, et al., (2015) Assistive technology-based programs to promote communication and leisure activities by three children emerged from a minimal conscious state. Cogn Process. 16(1): 69-78.

[30]. Stasolla F, De Pace C (2014) Assistive technology to promote leisure and constructive engagement by two boys emerged from a minimal conscious state. NeuroRehabilitation. 35(2): 253-9. 